\title{
Analyzing influencing factors to scale up agroforestry systems in Colombia: A comparative ex-ante assessment of cacao farming and cattle ranching in two regions
}

\author{
Tatiana Rodríguez (D) Michelle Bonatti • Katharina Löhr • Marcos Lana • \\ Martha Del Río · Stefan Sieber
}

Received: 30 July 2021 / Accepted: 30 December 2021 / Published online: 18 January 2022

(C) The Author(s) 2022

\begin{abstract}
Agroforestry systems (AFS) are proved to enhance sustainable land management. Thus, there is increasing demand for effective ways to scale up AFS so that more people can benefit. Consequently, this study assesses the scaling-up potential of agroforestry systems (AFS) using cacao farming and cattle ranching in Caquetá and Cesar, Colombia, as examples. An ex-ante assessment using the ScalA tool is conducted through interviews with AFS experts from institutions promoting AFS. Using a comparative approach, results reveal that AFS have different scaling-up
\end{abstract}

Supplementary Information The online version contains supplementary material available at https://doi.org/10.1007/ s10457-022-00730-1.

T. Rodríguez $(\bowtie) \cdot$ M. Bonatti · K. Löhr ·

M. Del Río - S. Sieber

Leibniz Centre for Agricultural Landscape Research

(ZALF), Sustainable Land Use in Developing Countries

(SusLAND), Müncheberg, Germany

e-mail: rodriguez@zalf.de

M. Bonatti $\cdot$ S. Sieber

Agricultural Economics, Humboldt-Universität zu Berlin,

Berlin, Germany

K. Löhr

Urban Plant Ecophysiology, Humboldt-Universität zu

Berlin, Berlin, Germany

M. Lana

Crop Production Ecology, Swedish University of

Agricultural Sciences, Uppsala, Sweden potential depending on the type of farming system and location characteristics. In our case, it is slightly higher for cacao farming than for cattle ranching in both regions and it is higher in Caquetá than in Cesar for both systems. Factors hindering the scaling-up potential for both regions are economic conditions at the local and regional levels since there is a lack of stable and differentiated markets to absorb AFS products. In contrast, the scaling-up potential in both regions is increased by the factors related to the capacity of the organizations that promote AFS and the attitudes of local communities toward them. The study generates information about factors that may hinder or foster AFS scaling-up, including not just the capacities and mechanisms to promote them but also the enabling conditions. This contributes to prioritizing AFS interventions and better allocating their resources to increase their chances of successful scaling-up.

Keywords Scaling-up · Impact assessment · Land management - Sustainable Cacao Production . Silvopastoral systems

\section{Introduction}

Agroforestry systems (AFS) are sustainable land management strategies that deliberately integrate woody perennials, herbaceous plants, livestock, and 
people, and their interactions with one another in farming and forest systems (Sinclair 1999; Zomer et al. 2009; Nair and Garrity 2012). These are traditionally employed by smallholder farmers throughout the tropics and promoted as a sustainable livelihood alternative by land-use managers and multilateral agencies through technical services, education, research, laws, and institutions (Zomer et al. 2009; Somarriba et al. 2012; Reij and Garrity 2016). AFS are considered key to reducing deforestation, facilitating ecosystem conservation, and mitigating and enhancing resilience to climate change (Pagiola et al. 2010; Lasco et al. 2014; Jacobi et al. 2015; Waldron et al. 2017; Nyong et al. 2020).

This is particularly important for a tropical emerging economy like Colombia, which has around $50 \%$ of its territory forested $\left(593,270 \mathrm{~km}^{2}\right)$, but is dealing with alarming deforestation rates. Approximately 1972 $\mathrm{km}^{2}$ were deforested in 2018 (SMByC, 2018). AFS are appropriate for $16.3 \%$ of Colombian land, not just balancing sustainable production against natural resource depletion (IGAC 2017) but also offering socioeconomic and environmental benefits at the farm level (Tapasco et al. 2019). However, AFS are not fully established on potential agricultural land and their contributions remain undeveloped, just as in the rest of the world (Das et al. 2021; Akamani and Holzmueller 2017; Montes-Londoño 2017; Guteta and Abegaz 2016; Jerneck and Olsson 2014). An adequate and careful process of AFS scaling-up could help to reduce pressures on natural forests, thus decreasing deforestation (Lerner et al. 2017; Castro-Nunez et al. 2021).

Cacao agroforestry systems (CAFS) could be considered a prevalent AFS type in Colombia since cacao crops are typically established and managed under shade by smallholder farmers with differing production practices dependent upon climate, soils, and household needs. CAFS tend to include banana plants, fruit trees, and shade trees mainly with timber species (Abbott et al. 2018), characteristics in line with CAFS definitions, which indicate they are complex multi-species cropping systems where cacao trees are associated with other permanent or temporary crops and with woody tree species (Cerda et al. 2014; Jagoret et al. 2014). However, CAFS still need better management since cacao yields are low and the potential benefits of harvesting timber are limited (Abbott et al. 2018).
On the other hand, silvopastoral systems (SPS) are an alternative for sustainably managing the already established cattle ranches in Colombia (Zuluaga and Etter 2018; Jose and Dollinger 2019), which traditionally have high environmental impact and low productivity, but are relevant in socioeconomic terms as they are deeply rooted in the culture and their derived products are still in high demand (Mauricio et al. 2018). SPS in Colombia combine fodder plants, like grasses and leguminous herbs, with shrubs and trees on the same unit of land, for mainly animal nutrition and comfort (Calle et al. 2013; Jose et al. 2019). Some examples include scattered trees in pasturelands, living fences, mixed fodder banks, and intensive silvopastoral systems (Calle et al. 2013).

As multiple AFS exist and their implementation is highly context dependent, there is no single formula to successfully scale up them (Franzel et al. 2004; Jerneck and Olsson 2014). Following the definition of Hartmann and Linn (2008), scaling-up refers to expanding, adapting, and sustaining successful policies, programs, or projects in different places and over time. However, it is not just about impact, scale, and sustainability, but it also involves a multidimensional process of change and adaptation that can be achieved by influencing the political processes, or by involving and working with other stakeholders and institutions.

Research shows the crucial role of service delivery mechanisms for AFS scaling-up, including participatory and farmer-centered research and extension approaches that facilitate cooperation between farmers, extensionists, and researchers. These approaches enable co-learning among AFS actors, helping to identify the most important knowledge gaps, thus prioritizing extension services and communication strategies, while a variety of technical options could be developed with fine-scale variations that adequately integrate trees, crops, and/or livestock within the farming systems considering the local circumstances (Franzel et al. 2004; Calle et al. 2013; Coe et al. 2014; Guteta and Abegaz 2016; Reij and Garrity 2016; Baig et al. 2020). An adequate institutional context is also relevant to scale up AFS, which implies not only the building of local institutional capacities or establishment of strategic partnerships (Franzel et al. 2004; Calle et al., 2013; Macke et al. 2021) but also institutional buy-in to influence the public policy agenda (Calle et al. 2013; Chavan et al. 2015; Reij and Garrity 2016). In addition, enabling economic and 
market conditions are needed to effectively scale up AFS (Baig et al. 2020), potentially including the development of certification programs or marketing strategies that help farmers to eliminate middle men or obtain premium prices (Guteta and Abegaz 2016; Reij and Garrity 2016; Pandit et al. 2019).

Existing studies typically focus on single farming systems and regions. However, a comparative approach will not just show the context specificity of AFS scaling-up but also identify factors influencing this process across farming systems and regions, thus being relevant to diverse stakeholders and contexts. Therefore, this study seeks to comparatively assess the hindering and fostering factors affecting the scalingup potential of SPS and CAFS across two regions of Colombia (Caquetá and Cesar). The study is guided by one research question: what are the hindering and fostering factors-including their interrelationshipsfor SPS and CAFS scaling-up in Caquetá and Cesar? Our hypothesis, based on the current literature, is that economic conditions might be the greatest hindrance to scaling-up SPS and CAFS in both regions. However, they are interacting with the social, institutional, and environmental conditions of each region that might also hamper this process.

\section{Methodology}

Study regions: Caquetá and Cesar departments of Colombia

The scaling-up potential of SPS and CAFS is investigated in two contrasting regions in Colombia, namely Caquetá and Cesar. Both are affected by high deforestation rates but in different ways due to their differing social, economic, and environmental conditions. Caquetá has abundant natural wealth, including water, due to its geographical location in the Amazonian region and the environmental regulation restricting land-based production activities (SIPRA 2019). However, it is at risk due to high deforestation rates (Castro-Nunez et al. 2021), which have increased since the peace agreement was signed in 2016 (Enciso et al. 2018). One main driver of deforestation is the expansion of pasturelands, reflecting that cattle ranching is the most representative economic activity there (Landholm et al. 2019). In contrast, Cesar, on the Caribbean plain, also hosts a high diversity of landscapes ranging from the mountain ranges of the Sierra Nevada de Santa Martha and the Serranía del Perijá to the valleys of the rivers Magdalena and Cesar (IGAC 2017). Palm oil cultivation and cattle ranching are the most relevant agricultural activities. Nevertheless, land occupation without environmental planning has brought about an acute loss of tropical dry forest and increased soil degradation. This situation has been exacerbated by the effects of climate change, which has led also to longer droughts and water shortages (ADR and FAO 2019).

Ex-ante assessment tool

An ex-ante assessment was conducted using the questionnaire of the Scaling-up Assessment Tool (ScalA). ScalA is designed to systematically assess (ex-ante) the degree of sustainability as well as the scaling-up potential of agricultural interventions (Crewett et al. 2005). The tool has been applied to studies assessing the scaling-up potential of a set of sustainable agricultural practices in a region (Jha et al. 2020; Sieber et al. 2015) or a sustainable strategy among a set of regions (Bonatti et al. 2017). The results of this ex-ante assessment could be useful to tailor sustainable AFS scaling-up interventions to the context, implement them through better planned strategies, and prevent negative impacts in local communities (Pope et al. 2013; Schindler et al. 2015).

ScalA only prompts for the scaling-up potential assessment if the agricultural intervention is perceived as sustainable. When this is verified through a checklist of 17 sustainability indicators, the scalingup potential assessment is conducted. For this purpose, the tool defines 59 scaling-up factors divided into 7 categories including AFS attributes, capacities of implementing organizations, attributes of AFS scaling-up strategies, national-level political/institutional framework, local institutional setting, local/regional economic conditions, and community attitudes toward AFS. The users score the compliance of these factors using a Likert-type scale with 0 if the factor is not met or not met at all, 1 if it is not completely met or there are some other limitations, and 2 if it is very much or very well met. The tool also weighs the importance of associated scaling-up factors by assessing the relevance of 11 financial, human, institutional, and agricultural inputs requirements for implementation using a scoring system between 0 (not relevant) and 3 
(significant). For example, a high financial capital requirement leads to a high relevance of the factor related to farmers' affordability to implement AFS. As a result, the user obtains a percentage that indicates a deviation of a current scaling-up situation from an optimal scaling-up situation where a predefined set of factors are fulfilled. Thus, a lower percentage denotes a higher chance for AFS scaling-up (Crewett et al. 2005; ZALF 2020).

\section{Data collection}

As scaling-up implies coordinated processes between stakeholders to expand and sustain AFS vertically (Hartmann and Linn, 2008), we conducted the ex-ante assessment of SPS and CAFS scaling-up potential with diverse stakeholders from Cesar and Caquetá using the ScalA questionnaire. It was applied 18 times through 16 interviews and 2 focus groups between February and May 2020, involving a total of 27 stakeholders (Table 1). These respondents were selected in two stages. First, we created a list of governmental and non-governmental institutions working on cacao farming and cattle ranching in both regions through a web search. Then, we chose experts to be interviewed from the list of institutions using three criteria: (1) their thorough knowledge about SPS or CAFS; (2) their experience with cacao farming or cattle ranching in Cesar or Caquetá; and (3) their experience implementing SPS or CAFS in one of the regions. The sample was diversified in terms of respondents' positions (regional heads, project coordinators, researchers, and technical assistants), institutional missions (extension, research, and education), and scale (national, regional, and local). Farmer perspectives were included in the sample since four technical advisors interviewed were farmers.

After conducting with respondents the sustainability assessment, they were not only asked to score the 59 scaling-up factors and 11 implementation requirements but also encouraged to comment on their scores. Scoring during the focus groups was done by consensus. Each interview lasted around $120 \mathrm{~min}$ and was conducted in Spanish face-to-face, by video call, or by phone call. Initially, all interviews were planned faceto-face; however, mobility restrictions due to the Covid-19 pandemic required methodological adaptions. All interviews were recorded and transcribed. To increase study reliability and validity, we also used secondary information (including papers, reports, and websites of organizations) to complement the empirical data.

Table 1 Number and nature of questionnaires conducted, stakeholders interviewed, and institutions involved in assessing scaling-up potential of SPS/CAFS in the two regions

\begin{tabular}{|c|c|c|c|c|}
\hline & $\begin{array}{l}\text { Cesar } \\
\text { SPS }\end{array}$ & CAFS & $\begin{array}{l}\text { Caquetá } \\
\text { SPS }\end{array}$ & CAFS \\
\hline $\begin{array}{l}\text { Number of questionnaires and } \\
\text { their method of application }\end{array}$ & $\begin{array}{l}\text { (5) Individual } \\
\text { interviews } \\
\text { (1) Focus group }\end{array}$ & $\begin{array}{l}\text { (5) Individual } \\
\text { interviews }\end{array}$ & $\begin{array}{l}\text { (3) Individual } \\
\text { interviews }\end{array}$ & $\begin{array}{l}\text { (3) Individual } \\
\text { interviews } \\
\text { (1) Focus group }\end{array}$ \\
\hline $\begin{array}{l}\text { Number and role of the } \\
\text { stakeholders interviewed }\end{array}$ & $\begin{array}{l}\text { (2) Project coordinators } \\
\text { (11) Researchers } \\
\text { (1) Technical advisor }\end{array}$ & $\begin{array}{l}\text { (1) Regional head } \\
\text { (1) Researcher } \\
\text { (3) Technical advisors }\end{array}$ & $\begin{array}{l}\text { (2) Project } \\
\text { coordinators } \\
\text { (1) Researcher }\end{array}$ & $\begin{array}{l}\text { (1) Regional head } \\
\text { (2) Researchers } \\
\text { (2) Technical advisors }\end{array}$ \\
\hline $\begin{array}{l}\text { Number and type of the } \\
\text { institutions involved }\end{array}$ & $\begin{array}{l}\text { (1) NGO } \\
\text { (1) Locally based rural } \\
\text { extension institution } \\
\text { (1) Regional university } \\
\text { (1) Livestock extension } \\
\text { institution } \\
\text { (1) Agricultural } \\
\text { research center }\end{array}$ & $\begin{array}{l}\text { (1) NGO } \\
\text { (1) Locally based rural } \\
\text { extension institution } \\
\text { (1) National federation } \\
\text { for cacao producers } \\
\text { (1) Agricultural } \\
\text { research institution } \\
\text { (1) Cacao trading } \\
\text { company }\end{array}$ & $\begin{array}{l}\text { (2) NGOs } \\
\text { (1) Agricultural } \\
\text { research } \\
\text { institution }\end{array}$ & $\begin{array}{l}\text { (1) National federation } \\
\text { for cacao producers } \\
\text { (2) Agricultural } \\
\text { research institutions }\end{array}$ \\
\hline
\end{tabular}


Data analysis

Respondents' verbal comments regarding individual scaling-up factors and resource requirements were analyzed via qualitative content analysis (Kohlbacher, 2006). The transcripts were paraphrased, abstracted, and reduced to preserve essential content, using as a coding system the scaling-up categories and resources requirements from ScalA tool.

For the quantitative analysis, average scores of the compliance of 59 scaling-up factors were calculated per system and per region to identify individual hindering and fostering factors. Average scores less than 1 denote hindering factors and average scores greater than 1 denote fostering factors. Furthermore, scores for the 11 different resource requirements were averaged by system and by region, facilitating the visualization of the most significant resource requirements affecting SPS and CAFS scaling-up in each region. The scaling-up percentage deviations of each interview and focus group (both total and by scalingup category) were automatically calculated by the ScalA tool. Finally, we calculated the averages of these percentage deviations by system, disaggregating them by region to allow for comparisons of the scaling-up categories between regions. The higher the percentage deviation of the category, the more it hinders scaling-up.

\section{Results}

Hindering and fostering factors to scale up SPS and CAFS

When assessing scaling-up potential through the 59 ScalA factors, some differences and commonalities between AFS and between regions emerge. These are presented here by scaling-up category; additional details are shown in Supplementary file 1.

\section{AFS attributes}

Regarding affordability, average scores show two hindering factors when scaling-up both AFS: farmers lack sufficient financial means and have difficulties accessing required external inputs. In terms of AFS complexity, results show that farmers need regular trainings to implement SPS in both regions and CAFS in Caquetá. According to CAFS experts in Cesar, these systems and related practices are known to farmers since they have traditionally managed permanent crops alongside agroforestry. Another factor potentially hindering AFS scaling-up is the level of social organization. This is why some interviewees agree that it is necessary to strengthen local social organizations when implementing CAFS projects. Finally, two factors potentially hinder SPS in both regions, albeit more critically in Cesar: farmers cannot quickly reap benefits and perceive a higher economic risk versus the alternatives. Regarding fostering factors, farmers tend to have easy access to organic inputs since their own organic waste can produce fertilizers; however, respondents perceive greater difficulty in accessing seeds and plant material, especially for implementing SPS in Cesar. All respondents also agree on: AFS can be tried out on small plots where benefits can easily be observed; AFS fit into existing production systems, thus increasing its long-term efficiency; and farmer autonomy and independence can thrive with AFS. SPS and CAFS also offer the potential for value-adding in order to increase benefits, but required structures have to be strengthened, mainly in Caquetá.

\section{Capacity of implementing organizations}

Interviewees generally perceive that a clear and transparent structure of the implementing organization is key for scaling-up. Especially in Caquetá, respondents appreciate the management and technical staff. Interviewed organizations do not just have strong leadership with a good reputation among beneficiaries, but they also have branch offices or a regional network comprising like-minded organizations. Organizations also have access to well-established networks of donors, policymakers, researchers, and private sector institutions, mainly in Caquetá due to its ecological importance. However, AFS promotion in both regions is restricted by the limited availability of technical staff.

\section{AFS scaling-up strategies attributes}

Generally, organizations have a clear definition of the scaling-up objective, a clear strategy for this objective, along with a well-established documentation, monitoring, and evaluation system. To promote AFS, they use effective dissemination channels, high-quality 
partnerships with farmers, and minimal incentives to introduce AFS. Some deficiencies are perceived by respondents regarding the engagement of their organizations in strengthening local organizations that support SPS promotion and implementation in both regions.

\section{National-level political/institutional framework}

Respondents perceive sociopolitical tensions that could hinder the scaling-up of SPS in both regions and CAFS in Caquetá. Moreover, the government still fails to effectively integrate AFS in formal curricula or in research and extension programs; this greatly hinders SPS scaling-up in both regions as they are not the traditional cattle ranching systems. Most respondents indicate that the governmental administrative system tries to support AFS scaling-up activities, but its agriculture and development agencies have limited efficiency or are physically absent. Finally, the governance system must be improved while scaling-up CAFS and SPS in both regions because there are decentralized structures that allow local solutions but lack effectiveness.

\section{Local institutional setting}

Generally, respondents report that local government development plans support AFS-related activities but lack financial and human capacities. Similarly, local associations are willing to support AFS activities, but they lack effectiveness and require strengthening. Experts also perceive unclear structures for land use and access due to informal land rights that might hinder AFS scaling-up, especially in Cesar.

\section{Local/regional economic conditions}

There are clearly more limitations for scaling-up SPS in both regions and CAFS in Cesar, since the predictability and attractiveness of market prices for cacao, fruits, milk, and meat produced under AFS are not advantageous compared to conventionally produced. However, while CAFS markets in Caquetá seem to guarantee better prices, their predictability and stability remain uncertain. Although there are multinational, national, and local food processing companies, who could benefit economically from AFS-derived agricultural products, their interest and support are uncertain. General infrastructural necessities, including access to roads, electricity, and water, are lacking in both regions. Availability of processing facilities is a hindering factor for both farming systems in both regions since farmers usually sell cacao and cattle products without any value-added transformation. Finally, AFS promoting organizations can help producers improve productivity, but accessing certification structures remains difficult.

\section{Community attitudes toward AFS}

AFS scaling-up could be fostered in both regions according to the respondents since not only does the majority of community members welcome AFS, but leaders also generally accept it. However, the limited number of young farmers interested in AFS and the limited number of community members engaged in entrepreneurial activities are concerning. Finally, although farmers are willing to actively participate in AFS project activities, concerns regarding cost/ labor-sharing and the needed human capacities remain.

Resource requirements influencing SPS and CAFS scaling-up

Figure 1 presents an overview of resources requirements and expert scores regarding perceived relevance for implementing SPS and CAFS.

Respondents perceive high financial capital is required to implement SPS and CAFS, in Caquetá slightly more than in Cesar. Know-how and skills are also perceived as medium or highly demanding for both systems, since both incorporate more elements into the agricultural system, thus requiring proper management. One interviewee notes this is relevant for both farmers and the staff advising them. These systems imply additional labor, perceived as medium or high for SPS; low or medium for CAFS. Some experts agree on the demand for financial capital, know-how, and additional labor depend on AFS complexity.

The need for specific agricultural and natural resource management laws as well as local institutions to scale up AFS is perceived as medium or high. The former is more required by SPS and the latter is more needed by CAFS in both regions. General infrastructure is perceived as a medium demanding resource for 


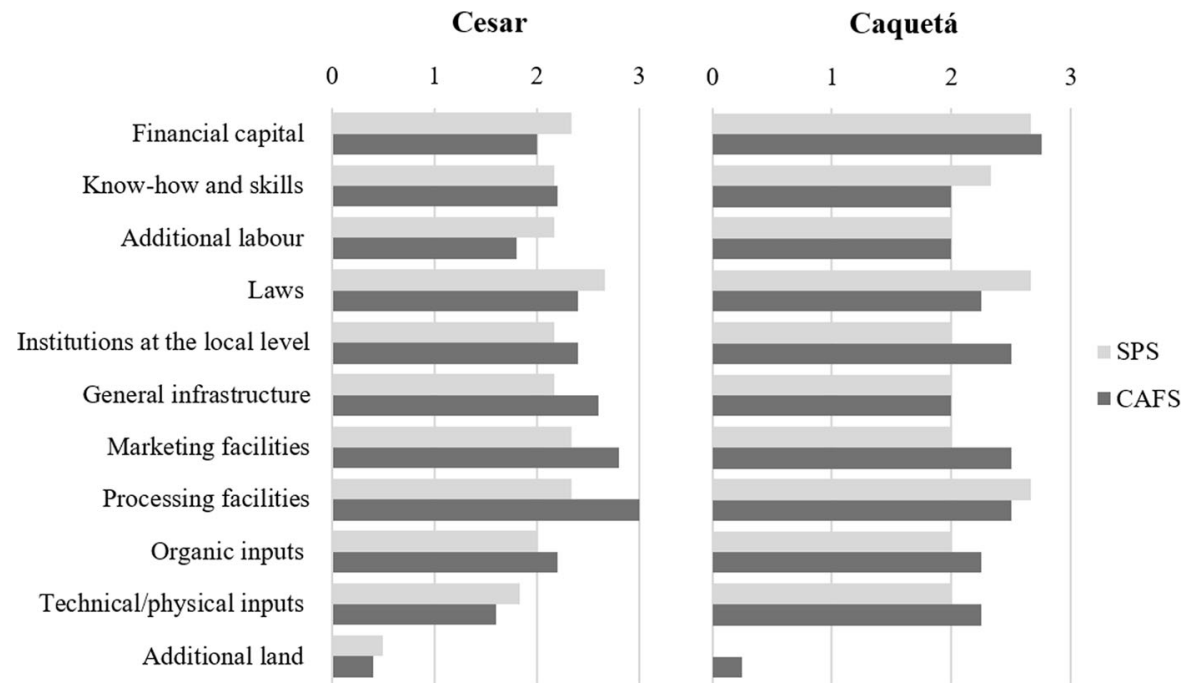

Fig. 1 Overview of financial, human, institutional, infrastructure, and agricultural input resources requirements for implementing Silvopastoral Systems (SPS) and Cacao Agroforestry

both systems in both regions. However, CAFS experts perceive that there is a slightly higher demand for infrastructure in Cesar since cacao farmers require a water distribution system. Similarly, demand for marketing facilities is generally perceived by experts as medium, since there are already local facilities where agricultural products of both systems could be sold. Processing facilities seem to constrain SPS and CAFS scaling-up in both regions since both require them at a medium or high level. For example, experts indicate that cacao producers in both regions typically lack adequate facilities for post-harvest processes.

In terms of external inputs, organic inputs are mostly assessed as a medium requirement. Technical and physical inputs are mostly assessed as a low or medium requirement in Cesar, but medium and high in Caquetá. Although these systems aim to reduce external fertilizers use, Caquetá's soils require them more than Cesar's soils. The demand for additional land is scored as not relevant or with a low relevance for both systems. Cattle farms are considered large enough in both regions, with SPS implementation implying less land due to its sustainable intensification practices. Cacao farms in Cesar are traditionally family farms unable to enlarge due to labor limitations.
Systems (CAFS) in Cesar and Caquetá. Experts scoring from 0 to 3: 0 = 'not relevant'; 1 = 'low'; 2 = 'medium'; 3 = 'high' $\left(\mathrm{n}_{\text {Cesar }}=11, \mathrm{n}_{\text {Caquetá }}=7\right)$

\section{SPS and CAFS scaling-up potential}

Regarding the total scaling-up potential for each system (Fig. 2), results show differences between AFS and regions, thus supporting the need to create context-specific interventions. Total average deviations from the optimal situation indicate that the potential for scaling-up SPS and CAFS is higher in Caquetá than in Cesar. This relates mainly to the capacities of implementing organizations in Caquetá. Of these farming systems, the scaling-up potential is slightly higher for CAFS than SPS, clearly in Cesar. This is an expected result since cacao farming systems in Colombia have traditionally been managed as AFS. There, the attributes of the system, the political/ institutional settings, the economic conditions, and community's attitudes pushed CAFS to be preferred over SPS, even though SPS is more favorably assessed with respect to institutional capacities and scaling-up strategies. In Caquetá, the results are similar, but the local institutional setting slightly favors scalability of SPS. The most hindering category for SPS and CAFS scaling-up in both regions refers to the local and regional economic conditions while the least hindering category has to do with the capacity of implementing organizations. 


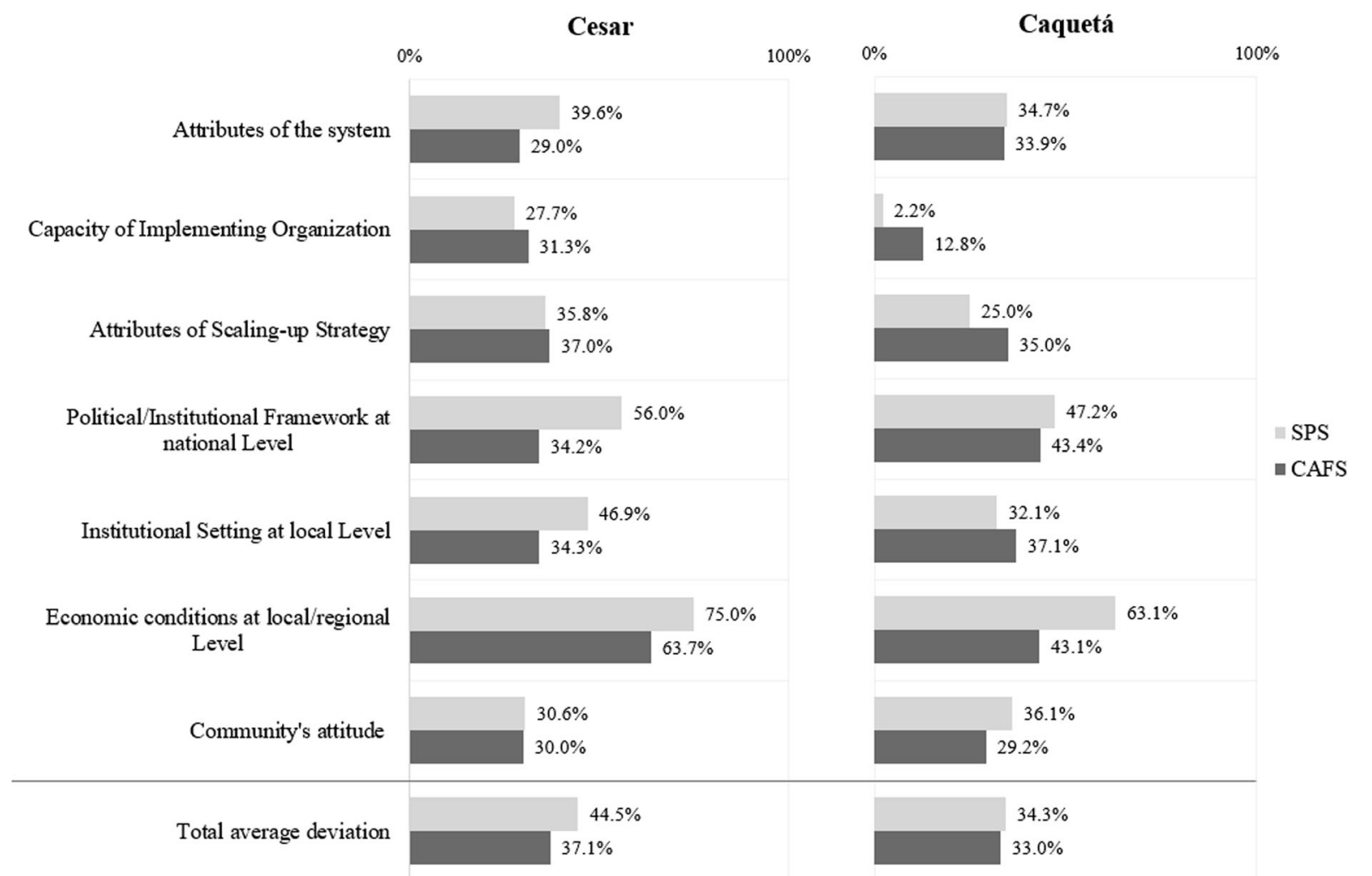

Fig. 2 Overview of 7 scaling-up categories of factors and average percentage deviation from the optimal scaling situation based on experts' scoring of resource requirement and rating of scaling-up factors. Lower percentages denote smaller deviations from the optimal situation, that is, categories that hinder less

\section{Discussion}

Our hypothesis was confirmed through this study: economic conditions are the greatest hindrance to SPS and CAFS scaling-up in both regions. In this sense, implementing organizations should encourage SPS and CAFS market-oriented interventions (Pandit et al., 2019), where producers associations are strengthened and connected with the private sector to establish marketing platforms, especially for meat, milk, and dried cacao. For value-added products, like cheese derived from SPS, the focus should be on supporting and strengthening local value chains, as Reij and Garrity (2016) suggest, through the improvement and formalization of storage and processing facilities. Other strategy should be technically and economically supporting farmers on getting certifications (e.g., organic) to obtain premium prices (Andres et al. 2016; Guteta and Abegaz 2016; Rosati et al. 2021).
SPS/CAFS scaling-up. Higher percentages denote higher deviations from the optimal situation, that is, categories that hinder more SPS/CAFS scaling-up. The last bars show the total average deviation; $\left(\mathrm{n}_{\text {Cesar }}=11, \mathrm{n}_{\text {Caquetá }}=7\right)$

AFS scaling-up is also influenced by the social, institutional, and biophysical conditions of the regions as well as the resources required to implement and sustain these systems. Like other studies (Mahecha 2003; Calle et al. 2009; Chitakira and Torquebiau 2010), we find the assessed AFS require medium to high financial capital for the establishment and maintenance, something farmers typically lack. To overcome this hindrance, low-cost SPS arrangements using natural regeneration of native trees could be promoted in both regions. Natural regeneration costs nothing in some cases because new trees grow without nurturing or protection (Reij and Garrity 2016), and it provides an opportunity to restore degraded lands (Mauricio et al. 2018). In the case of CAFS, organic management could also be encouraged in both regions to decrease financial capital required and increase farm income since it does not seem to negatively affect cacao yields or incidence of pests and diseases 
(Padmavathy and Poyyamoli 2013; Schneider et al. 2017; Armengot et al. 2020). Another strategy could be focused on encouraging SPS and CAFS establishment by providing incentives, like external agricultural inputs (Chitakira and Torquebiau 2010). However, these incentives must be well planned, adapted, and monitored because they could affect the intrinsic motivations of farmers to implement these sustainable systems. For example, Kakhobwe et al. (2016) state that the long-term provision of agricultural inputs could negatively affect AFS scaling-up by farmers.

Farmers also need greater technical knowledge and skills when managing SPS and CAFS. As this hinders AFS scaling-up, more effective extension services must be provided. Here, the active involvement and integration of farmers with extension workers and researchers through on-farm demonstration plots is key: farmers will not just help to setup, manage, and monitor these plots, but will also support AFS scalingup after observing its benefits (Bertin et al. 2014; Jagoret et al. 2014; Kakhobwe et al. 2016; Guteta and Abegaz 2016). Farmers input is crucial in planning where and which tree and shrubs species to plant, as they know which are complementary to their crops and cattle (Jose et al. 2019; Baig et al. 2020). Promoting farmer participation in research and extension seems viable, as scaling-up factors related to community attitudes toward AFS are positively assessed. Further, training AFS staff is essential to enhance its scaling-up (e.g., Chitakira and Torquebiau 2010; Landicho et al. 2009).

Although the literature suggest that the integration of trees, crops, and/or livestock through AFS can contribute toward resource use efficiency and sustainable livelihoods, these systems must be well integrated considering the local biophysical and socioeconomic conditions. For example, SPS and CAFS scaling-up potential in both regions decreases due to perceptions of higher economic risk. For SPS, it might be associated with biophysical conditions of the regions (e.g., long droughts in Cesar, floods in Caquetá) that hamper the survival and growth of plants when establishing them. For CAFS, it might be related to incipient timber markets, as the producer's ability to harvest and sell it is limited due to governmental policies (Abbott et al. 2018).

Although specific agricultural and natural resource management laws are needed for AFS scaling-up, no established framework or specific law for AFS exists in Colombia, just as in other countries (Macke et al. 2021). However, as Callo-Concha et al. (2017) point out, given its diverse practices, AFS is affected by multiple policies. Thus, a legislative framework that comprehensively supports AFS is a policy challenge to address at the national level.

Franzel et al. (2004) identify the building of local institution capacity as a key factor for scaling-up AFS. This is consistent with our results, which indicate strengthened local social organizations will effectively underpin scaling-up AFS. These organizations will not only sustain AFS in the long term but also facilitate the understanding and mitigation of unintended effects (Castro-Nunez et al., 2021). However, the scaling-up assessment shows that local governments and local-based organizations in the regions lack institutional capacities, while AFS supportive organizations often lack strategies to strengthen localbased organizations, especially in Cesar. Here, establishing strategic public-private partnerships could support AFS scaling-up, as highlighted in existing studies (Chavan et al. 2015; Macke et al. 2021).

\section{Conclusions}

This comparative approach shows how context-specific AFS interventions must be planned in order to increase their effectiveness and their subsequent scaling-up. However, it also identifies some commonalities relevant to other regions and farming systems. To scale up AFS, enabling economic conditions that protect farmers against market risks, either by seeking more favorable prices or by strengthening local value chains to generate greater added value, is critical. Further, AFS projects should incentivize farmers to establish AFS while promoting low-cost arrangements based on local farmer-centered research and planning, facilitating compatible and synergetic relationships between AFS elements. Considering the complexity of AFS implementation and management, institutions supporting AFS should actively bring farmers, extension workers, and agricultural researchers together. Strategic partnerships between public, private, and local organizations should be established to facilitate and guarantee AFS sustainability.

However, study limitations must be considered when observing its results. First, broad definitions of 
SPS and CAFS are considered; however, particular arrangements of these systems may have different scaling-up implications. Second, the case study approach followed, focusing on two AFS and two regions, may limit the generalizability of the findings. Third, although the most experienced and knowledgeable respondents of AFS-related institutions were interviewed, including some farmers, considering a broader set of perspectives would provide more insights into AFS scaling-up hindrances.

Acknowledgements The authors thank all those who kindly agreed to be interviewed in both regions.

Authors' contributions Conceptualization: [Tatiana Rodríguez, Michelle Bonatti, Katharina Löhr, Marcos Lana, Martha Del Río, Stefan Sieber]; Methodology: [Tatiana Rodríguez, Michelle Bonatti, Katharina Löhr, Marcos Lana, Martha Del Río, Stefan Sieber]; Formal analysis and investigation: [Tatiana Rodríguez]; Writing-original draft preparation: [Tatiana Rodríguez]; Writing-review and editing: [Tatiana Rodríguez, Michelle Bonatti, Katharina Löhr, Marcos Lana, Martha Del Río, Stefan Sieber]; Funding acquisition: [Michelle Bonatti, Marcos Lana, Stefan Sieber]; Supervision: [Katharina Löhr, Michelle Bonatti, Marcos Lana, Stefan Sieber].

Funding Open Access funding enabled and organized by Projekt DEAL. This research was supported by the project "Implementing sustainable agricultural and livestock systems for simultaneous targeting of forest conservation for climate change mitigation (REDD + ) and peace-building in Colombia," which is part of the International Climate Initiative (IKI). The Federal Ministry for the Environment, Nature Conservation and Nuclear Safety (BMU) supports this initiative on the basis of a decision adopted by the German Bundestag (https://www.international-climate-initiative.com/).

Availability of data and material The data that support the findings of this study are available on request from the corresponding author, Tatiana Rodríguez. The data are not publicly available because it contains information that could compromise the privacy of research participants.

Code availability Not applicable.

\section{Declarations}

Conflict of interest All authors are free of competing interests.

Ethical approval This research is part of the project "Implementing sustainable agricultural and livestock systems for simultaneous targeting of forest conservation for climate change mitigation (REDD + ) and peace-building in Colombia," which was reviewed and approved by the Institutional Review Board (IRB) of the Alliance Bioversity-CIAT. The IRB reviews all research that involves human participants to ensure their protection.

Consent to participate Informed consent was obtained from all individual participants included in the study.

Consent for publication All individual participants provided informed consent for using their data anonymously in research publications.

Open Access This article is licensed under a Creative Commons Attribution 4.0 International License, which permits use, sharing, adaptation, distribution and reproduction in any medium or format, as long as you give appropriate credit to the original author(s) and the source, provide a link to the Creative Commons licence, and indicate if changes were made. The images or other third party material in this article are included in the article's Creative Commons licence, unless indicated otherwise in a credit line to the material. If material is not included in the article's Creative Commons licence and your intended use is not permitted by statutory regulation or exceeds the permitted use, you will need to obtain permission directly from the copyright holder. To view a copy of this licence, visit http://creativecommons.org/licenses/by/4.0/.

\section{References}

Abbott PC, Benjamin T, Burniske G, et al (2018) An analysis of the supply chain of cacao in Colombia. United States Agency for International Development USAID, Cali

ADR, FAO (2019) Plan Integral de Desarrollo Agropecuario y Rural con Enfoque Territorial Departamento del Cesar. Bogotá D.C.

Akamani K, Holzmueller EJ (2017) Socioeconomic and Policy Considerations in the Adoption of Agroforestry Systems: An Ecosystem-based Adaptive Governance Approach. In: Dagar JC, Tewari VP (eds) Agroforestry: Anecdotal to Modern Science. Springer, Singapore, pp 833-855

Andres C, Comoé H, Beerli A, et al (2016) Cocoa in Monoculture and Dynamic Agroforestry. In: Sustainable Agriculture Reviews. Springer, Cham, pp 121-153

Armengot L, Ferrari L, Milz J et al (2020) Cacao agroforestry systems do not increase pest and disease incidence compared with monocultures under good cultural management practices. Crop Prot. https://doi.org/10.1016/j.cropro.2019. 105047

Baig MB, Burgess PJ, Fike JH (2020) Agroforestry for healthy ecosystems: constraints, improvement strategies and extension in Pakistan. Agrofor Syst 95:995-1013. https:// doi.org/10.1007/s10457-019-00467-4

Bertin T, Zacharie T, Ann D et al (2014) Scaling-up sustainable land management practices through the concept of the rural resource centre: reconciling farmers' interests with research agendas. J Agric Educ Ext 20:463-483. https:// doi.org/10.1080/1389224X.2014.913984

Bonatti M, Homem LHIR, Graef F et al (2017) Social organization, constraints and opportunities for kitchen garden 
implementation: ScalA and ScalA-FS assessment tools in Morogoro and Dodoma, Tanzania. Food Secur 9:1299-1308. https://doi.org/10.1007/s12571-017-0726-7

Calle A, Montagnini F, Zuluaga AF (2009) Farmer's perceptions of silvopastoral system promotion in Quindio, Colombia. Bois Forets Des Trop 300:79-94. https://doi. org/10.19182/bft2009.300.a20417

Calle Z, Murgueitio E, Chará J et al (2013) A strategy for scaling-up intensive silvopastoral systems in Colombia. J Sustain for 32:677-693. https://doi.org/10.1080/ 10549811.2013.817338

Callo-Concha D, Denich M, Ul Hassan MM et al (2017) Lessons for research, capacity development and policy in agroforestry for development. Agrofor Syst 91:795-798. https://doi.org/10.1007/s10457-017-0085-6

Castro-Nunez A, Buritic A, Gonzalez C et al (2021) The risk of unintended deforestation from scaling sustainable livestock production systems. Conserv Sci Pract. https://doi. org/10.1111/csp2.495

Cerda R, Deheuvels O, Calvache D et al (2014) Contribution of cocoa agroforestry systems to family income and domestic consumption: looking toward intensification. Agrofor Syst 88:957-981. https://doi.org/10.1007/s10457-014-9691-8

Chavan SB, Keerthika A, Dhyani SK et al (2015) National Agroforestry Policy in India: a low hanging fruit. Curr Sci 108:1826-1834. https://doi.org/10.18520/cs/v108/i10/ $1826-1834$

Chitakira M, Torquebiau E (2010) Barriers and coping mechanisms relating to agroforestry adoption by smallholder farmers in Zimbabwe. J Agric Educ Ext 16:147-160. https://doi.org/10.1080/13892241003651407

Coe R, Sinclair F, Barrios E (2014) Scaling up agroforestry requires research "in" rather than "for" development. Curr Opin Environ Sustain 6:73-77. https://doi.org/10.1016/j. cosust.2013.10.013

Crewett W, Bridge F, Sieber S (2005) Scaling up of Good Agricultural Practices. The Operational Assessment Tool ScalA. Leibniz Centre for Agricultural Landscape Research, Müncheberg

Das AK, Rahman MA, Rahman MM et al (2021) Scaling up of jujube-based agroforestry practice and management innovations for improving efficiency and profitability of land uses in Bangladesh. Agrofor Syst. https://doi.org/10.1007/ s10457-021-00656-0

Enciso K, Bravo A, Charry A, et al (2018) Estrategia sectorial de la cadena de ganadería doble propósito en Caquetá, con enfoque agroambiental y cero deforestación. International Center for Tropical Agriculture, Cali

Franzel S, Denning GL, Lillesø JPB, Mercado AR (2004) Scaling up the impact of agroforestry: Lessons from three sites in Africa and Asia. Agrofor Syst 61-62:329-344. https://doi.org/10.1023/B:AGFO.0000029008.71743.2d

Guteta D, Abegaz A (2016) Factors influencing scaling up of agroforestry-based spatial land-use integration for soil fertility management in Arsamma Watershed, Southwestern Ethiopian Highlands. J Environ Plan Manag 59:1795-1812. https://doi.org/10.1080/09640568.2015. 1090960

Hartmann A, Linn J (2008) Scaling Up: A Framework and Lessons for Development Effectiveness from Literature and Practice. Wolfensohn Center for Development, Washington D.C.

IGAC (2017) Estudio general de suelos y zonificación de tierras. Departamento del Cesar Escala 1:100.000. Instituto Geográfico Agustín Codazzi, Bogotá

Jacobi J, Schneider M, Bottazzi P et al (2015) Agroecosystem resilience and farmers' perceptions of climate change impacts on cocoa farms in Alto Beni, Bolivia. Renew Agric Food Syst 30:170-183. https://doi.org/10.1017/ S174217051300029X

Jagoret P, Kwesseu J, Messie C et al (2014) Farmers' assessment of the use value of agrobiodiversity in complex cocoa agroforestry systems in central Cameroon. Agrofor Syst 88:983-1000. https://doi.org/10.1007/s10457-014-9698-1

Jerneck A, Olsson L (2014) Food first! Theorising assets and actors in agroforestry: Risk evaders, opportunity seekers and "the food imperative" in sub-Saharan Africa. Int J Agric Sustain 12:1-22. https://doi.org/10.1080/14735903. 2012.751714

Jha S, Kaechele H, Lana M et al (2020) Exploring farmers' perceptions of agricultural technologies: a case study from Tanzania. Sustainability 12:1-21. https://doi.org/10.3390/ su12030998

Jose S, Dollinger J (2019) Silvopasture: a sustainable livestock production system. Agrofor Syst 93:1-9. https://doi.org/ 10.1007/s10457-019-00366-8

Jose S, Walter D, Mohan Kumar B (2019) Ecological considerations in sustainable silvopasture design and management. Agrofor Syst 93:317-331. https://doi.org/10.1007/ s10457-016-0065-2

Kakhobwe CM, Kamoto JF, Njoloma JP, Ozor N (2016) Scaling up agroforestry farming systems: lessons from the Malawi agroforestry extension project. J Agric Ext 20:153-162. https://doi.org/10.4314/jae.v20i1.13

Kohlbacher F (2006) The use of qualitative content analysis in case study research. Forum Qual Sozialforsch. https://doi. org/10.17169/fqs-7.1.75

Landholm DM, Pradhan P, Wegmann P et al (2019) Reducing deforestation and improving livestock productivity: greenhouse gas mitigation potential of silvopastoral systems in Caquetá. Environ Res Lett 14:114007. https://doi. org/10.1088/1748-9326/ab3db6

Landicho LD, Cabahug RD, De Luna CC (2009) Engaging in school-led multisectoral collaboration: implications to agroforestry promotion in the Philippine uplands. J Agric Educ Ext 15:69-79. https://doi.org/10.1080/ 13892240802617502

Lasco RD, Delfino RJP, Catacutan DC et al (2014) Climate risk adaptation by smallholder farmers: the roles of trees and agroforestry. Curr Opin Environ Sustain 6:83-88. https:// doi.org/10.1016/j.cosust.2013.11.013

Lerner AM, Zuluaga AF, Chará J et al (2017) Sustainable cattle ranching in practice: moving from theory to planning in Colombia's livestock sector. Environ Manage 60:176-184. https://doi.org/10.1007/s00267-017-0902-8

Macke J, Bozhikin I, Sarate JAR (2021) Feeding a growing population without deforestation: agroforestry system partnerships and mechanisms. Agrofor Syst 95:687-706. https://doi.org/10.1007/s10457-021-00621-x 
Mahecha L (2003) Importancia de los sistemas silvopastoriles y principales limitantes para su implementación en la ganadería colombiana. Rev Colomb Ciencias Pecu 16:18

Mauricio RM, Ribeiro RS, Paciullo DSC, et al (2018) Silvopastoral systems in Latin America for biodiversity, environmental, and socioeconomic improvements. In: Agroecosystem Diversity: Reconciling Contemporary Agriculture and Environmental Quality. Academic Press, pp 287-297

Montes-Londoño I (2017) Tropical Dry Forests in Multi-functional Landscapes: Agroforestry Systems for Conservation and Livelihoods. In: Integrating Landscapes: Agroforestry for Biodiversity Conservation and Food Sovereignty. Springer, Cham, pp 47-78

Nair PKR, Garrity D (2012) Agroforestry - The future of global land use. Springer, Gainesville

Nyong AP, Ngankam TM, Felicite TL (2020) Enhancement of resilience to climate variability and change through agroforestry practices in smallholder farming systems in Cameroon. Agrofor Syst 94:687-705. https://doi.org/10. 1007/s10457-019-00435-y

Padmavathy A, Poyyamoli G (2013) Role of agro-forestry on organic and conventional farmers' livelihood in Bahour, Puducherry-India. Int J Agric Sci 2:400-409

Pagiola S, Rios AR, Arcenas A (2010) Poor Household participation in payments for environmental services: lessons from the Silvopastoral Project in Quindío, Colombia. Environ Resour Econ 47:371-394. https://doi.org/10.1007/ s10640-010-9383-4

Pandit BH, Nuberg I, Shrestha KK et al (2019) Impacts of market-oriented agroforestry on farm income and food security: insights from Kavre and Lamjung districts of Nepal. Agrofor Syst 93:1593-1604. https://doi.org/10. 1007/s10457-018-0273-z

Pope J, Bond A, Morrison-Saunders A, Retief F (2013) Advancing the theory and practice of impact assessment: setting the research agenda. Environ Impact Assess Rev 41:1-9. https://doi.org/10.1016/j.eiar.2013.01.008

Reij C, Garrity D (2016) Scaling up farmer-managed natural regeneration in Africa to restore degraded landscapes. Biotropica 48:834-843. https://doi.org/10.1111/btp.12390

Rosati A, Borek R, Canali S (2021) Agroforestry and organic agriculture. Agrofor Syst 95:805-821. https://doi.org/10. 1007/s10457-020-00559-6

Schindler J, Graef F, König HJ (2015) Methods to assess farming sustainability in developing countries. A Rev Agron Sustain Dev 35:1043-1057. https://doi.org/10.1007/ s13593-015-0305-2

Schneider M, Andres C, Trujillo G et al (2017) Cocoa and total system yields of organic and conventional agroforestry vs. monoculture systems in a long-term field trial in Bolivia. Exp Agric 53:351-374. https://doi.org/10.1017/ S0014479716000417

Sieber S, Jha S, Tharayil Shereef AB et al (2015) Integrated assessment of sustainable agricultural practices to enhance climate resilience in Morogoro, Tanzania. Reg Environ Chang 15:1281-1292. https://doi.org/10.1007/s10113015-0810-5

Sinclair FL (1999) A general classification of agroforestry practice. Agrofor Syst 46:161-180. https://doi.org/10. 1023/A: 1006278928088

Sistema de monitoreo de bosques y carbono SMByC (2018) Reporte de Cambio de la Superficie Cubierta por Bosque Natural (Nacional). In: Inst. Hidrol. Meteorol. y Estud. Ambient. http://smbyc.ideam.gov.co/MonitoreoBC-WEB/ pub/reporteGeoproceso.jsp?id_reporte $=7297$

Sistema para la Planificación Rural Agropecuaria SIPRA (2019) Estadísticas Frontera Agrícola. In: Unidad Planif. Rural Agropecu. https://sipra.upra.gov.co/

Somarriba E, Beer J, Alegre-Orihuela J et al (2012) Mainstreaming Agroforestry in Latin America. In: Nair R, Garrity D (eds) Agroforestry-the future of global land use. Springer, Dordrecht, pp 429-453

Tapasco J, LeCoq JF, Ruden A et al (2019) The livestock sector in Colombia: toward a program to facilitate large-scale adoption of mitigation and adaptation practices. Front Sustain Food Syst 3:1-17. https://doi.org/10.3389/fsufs. 2019.00061

Waldron A, Garrity D, Malhi Y et al (2017) Agroforestry can enhance food security while meeting other sustainable development goals. Trop Conserv Sci 10:1-6. https://doi. org/10.1177/1940082917720667

ZALF (2020) ScalA - Sustainability Impact Assessment tool. https://www.zalf.de/en/forschung_lehre/software_ downloads/Pages/default.aspx

Zomer R, Trabucco A, Coe R, Place F (2009) Trees on Farm: Analysis of Global Extent and Geographical Patterns of Agroforestry. World Agroforestry Centre, Nairobi

Zuluaga A, Etter A (2018) Áreas aptas para la actividad ganadera en Colombia. In: Moreno L, Rueda C, Andrade G (eds) Biodiversidad 2017. Estado y tendencias de la biodiversidad continental de Colombia. Instituto de Investigación de Recursos Biológicos Alexander von Humboldt, Bogotá D.C., p 67

Publisher's Note Springer Nature remains neutral with regard to jurisdictional claims in published maps and institutional affiliations. 